Margarita Todorova*

DOI: 10.2478/v10241-012-0013-7

Georgi Todorov

\title{
Multimedia technologies and ICT in organising e-portfolio for students
}

\section{ABSTRACT}

An electronic portfolio, also known as an e-portfolio or digital portfolio, is a collection of electronic evidence assembled and managed by a user, usually on the Web. Such electronic evidence may include inputted text, electronic files such as Microsoft Word and Adobe PDF files, images, multimedia, Blog entries, and hyperlinks.

One of the approaches, which can be used for improving the attractiveness of the e-portfolio is presented, and it is an implementation of the multimedia technologies in it. In this case we are speaking about multimedia electronic portfolio. What makes them very different from the traditional portfolios is that they can include scanned or digital photos, video and sound clips, animations, recordings of the students, text, traditional writings and drawings.

Two main groups of tools (Non Web Authoring Tools and Web Authoring Tools) for creating multimedia e-portfolio are presented.

KEYWORDS: e-portfolio, Technological Change: Choices and Consequences; Diffusion Processes

* Correspondence regarding the paper should be sent to: Margarita Todorova, University St. Cyril And St. Methodius 2, Teodosij Turnovski Str., 5003 Veliko Turnovo, Bulgaria. 


\section{INTRODUCTION}

The use of modern multimedia technologies and ICT for organising professional e-portfolios for students at the Universities is discussed in this paper. Structuring web-pages, web-sites or blogs with multimedia characteristics as possible tools for organising student's e-portfolio is also presented.

The Lisbon strategy for creating European educational space and the Bologna declaration specify the following priority actions:

- Studying as a value;

- Information, management and advice;

- Investment of time and resources;

- Removal of the gap between people and educational/learning opportunities;

- Creating portfolios allowing citizens to present their professional qualifications all over Europe;

- Innovative study approaches;

- Creating Internet-based educational portals.

From the above, it can be seen that the creating portfolios for citizens in general, and for students in particular, is one of the priority activities.

The most general definition of a portfolio is "records of separate steps of progress of the individuals". In education, portfolio refers to a personal collection of information describing and documenting a person's achievements and learning.

Portfolio can be designed as a file containing students' achievements (as documents and related materials) on different aspects: educational, social, communication, and creativity for a certain period of time. It contains a collection of projects and tasks performed during the study, personal achievements, improving personal professional qualifications etc. It can present a wide range of aspects of students' work, successes and problems. The portfolio serves as a way for the self assessment 
(reasoning, argumentation) of one's own cognitive and creative work, based on the mechanism of reflection.

When a portfolio is stored in an electronic container (CD, DVD), or published in virtual web space we refer to electronic portfolios. An electronic portfolio, also known as an e-portfolio or digital portfolio, is a collection of electronic evidence assembled and managed by a user, usually on the Web. Such evidence may include inputted text, electronic files such as Microsoft Word and Adobe PDF files, images, multimedia, blog entries, and hyperlinks.

Two visions to student portfolio are possible:

1. From the side of the individual - a private portfolio, which shows education, skills, and interests to everybody, who is interested. The information and data published here are sometimes of subjective nature;

2. From the side of administration - let us say it is an official portfolio. The organisation and contents of such portfolios are oriented mainly towards presenting a person as a component (element) in the organizational structure of the university. The data have to be objective and able to predict the person's progress and support the decision making process when it is necessary.

Naturally, the primary benefit for the faculty is to provide a tool for better management and reviewing of, and reflecting and commenting, on students' work. Administrators may see the value of ePortfolios for the following reasons:

- Creating a system of tracking student work over time, in a single course, with both the students and the faculty reflecting on it;

- Aggregating many students' work in a particular course to see how the students are progressing toward learning goals as a whole; 
- Assessing many courses in similar ways that are all part of a major one and thus, by extension, assessing the entire program of study.

Ultimately, all these benefits provide administrators with highly useful data for accreditation. Further, they may discover how to:

- Integrate courses with new methods, orienting syllabi and curricula around learning goals;

- Encourage continuity of student work from semester to semester in linked courses;

- Have a more fully informed and dynamic, constantly updated view of their students' progress in a program, which is very helpful in formative assessment.

In this context and in terms of technology, a digital story is a digital video clip, told in the author's own voice, illustrated mostly with still images, with an optional music track added for emotional effect. Rhetorically, a digital story is a personal narrative that may show the author's identity: strengths, weaknesses, achievements, disappointments, learning experiences, passions, and hopes for the future; in other words: reflection.

Voice, as defined above, is often missing from electronic portfolios, both literally and rhetorically. A digital story provides that voice: listening to the author, we hear a real person, getting a sense of their unique personality. [2] One of the approaches of improving attractiveness of the portfolio is using multimedia technologies for its development.

What makes them very different from traditional portfolios is that they can include scanned or digital photos, video and sound clips, animations, recordings of students, text, traditional writings and drawings

A portfolio is to display one's talents and proficiencies demonstrating one's knowledge and skills. The question that one should ask is "What am I trying to tell the reader about myself?" How one answers this question depends on the targeted audi- 
ence. It ought to be remembered that the portfolio is a personal reflection, and thus should look very professional and different tools should be used for its creation.

The main arguments for using multimedia objects in e-portfolios are the following:

- perceiving the facts from the portfolio becomes easier;

- opportunity for presenting large volumes of information (a picture or a fragment of music can contain much more information than a plain text file);

- when a person is reading, looking at and listening to at the same time, he is receives and apprehends much more information than when he is only reading, looking at or listening;

- possibility for creating compact portfolios using links to different multimedia objects;

- implementation and use of WYSIWIG (What You See Is What You Get) technology;

- as a side effect, there is the possibility of including legacy and memoir issues in e-portfolios.

Digital stories can provide us with an opportunity to leave a legacy of our family stories for those who come after us. Legacy stories are usually told about a person or a place.

In contrast to a legacy story, a memoir is very personal, told in the first person, focusing on the memories of the storyteller. Memoirs are autobiographical in nature, but much more personal and reflective. They are usually much longer than a typical digital story.

BASIC TOOLS FOR CREATING AND DEVELOPING E-PORTFOLIOS

\section{Hyperstudio}

Hyperstudio is a program, which can be recommended as a multimedia authoring software for electronic portfolios. It is particularly useful in terms of literacy because you can include 
text boxes with almost unlimited space for typing and importing from a word processor. It is a powerful multimedia tool that increases student achievement. Its advantages also include improved problem-solving and creative thinking skills, appeal to a wide variety of student interests and learning styles, and reinforcement of student development in project-based education. It is an easy-to-use multimedia authoring tool which allows incorporation of text, graphics, sound, video, hyperlinks and active URLs into one's e-portfolio.

\section{Power Point}

A Power Point software package can also be used for creating an electronic portfolio. Power Point allows the user to select a presentation design that automatically generates a background theme. The user can also create his/her own background with fills, pictures, textures, etc. The second screen provides an interactive menu with each button linking to another slide. Navigational buttons allow the user to go to the next slide, the previous slide, or the home page menu from each slide. You can create buttons that link to another Power Point presentation, another document or spreadsheet, an Acrobat Reader pdf file, or another program application. The page layout will depend on whether one is bringing in text, graphics, tables, or charts.

In addition, a multimedia electronic portfolio can be created with an interactive menu using Power Point. Rather than creating a linear slide by slide Power Point, one can create a menu with links to slides of his/her artefacts. Each button will link directly to the different slide topics. You can also create navigation buttons in the auto shapes menu. They are called action buttons and you edit those from the slide show menu.

\section{Web Authoring Tools}

This section contains a listing of direct links to the most widely used HTML editors and site management tools. Many of the 
editors listed below are What You See Is What You Get (WYSIWYG) HTML editors, some of which have the option to view the HTML source code. These are quite popular due to the low learning curve.

The Web Authoring Tools are divided into three parts: HTML/Text Editors, Site Management/HTML Editing Tools, and Additional Resources. A list of the more widely used tools is given below.

\section{HTML/TEXT EDITORS}

\section{Adobe PageMill}

Adobe PageMill is a WYSIWYG HTML editor, equipped with an interface that allows users to "view-as-you-create." Users can opt to view and edit the HTML source code. This application also supports frames/tables, site upload via FTP, and text imports from programs such as Microsoft Word, Corel WordPerfect, Microsoft Excel, dBASE, and others. It is provided by Adobe Systems Inc. for both Macintosh and Windows platforms.

\section{AOLPress}

AOLpress is a free WYSIWYG HTML editor that offers a WYSIWYG and HTML editing mode. MiniWeb, a feature capable of functioning as a simple site manager, also allows for existing HTML files to be easily imported. The editor also supports auto creation of tables, frames, lists, and various other page attributes with the click of a button. Pages can be published on non-AOL servers that support the HTTP PUT protocol. It is provided by America Online, Inc. and is available for Macintosh, Unix, and Windows. 


\section{BBEdit}

BBEdit is a text and HTML editor available for Macintosh only (non-WYSIWYG). This editor offers great functionality and control over HTML code. As a powerful text editor, it offers features such as multiple undo, multi-file find and replace, the capability to read all DOS/Unix/Mac files up to 2 GB in size, and more. At the same time, acting as an HTML editor, it offers HTML specific features such as floating tool palettes, syntax coloration, and HTML syntax checking. Using this editor with a browser is as simple as clicking a button, allowing one to view a web page as it is created. It also supports many programming languages including $\mathrm{C} / \mathrm{C}++, \mathrm{HTML}$, Java, Perl, Pascal, Assembly language, Fortran, TeX, etc.

\section{Crackerjack}

Crackerjack is a non-WYSIWYG HTML editor, available for Microsoft Word 6.0 and later editions, used to create web pages. HTML code is inserted into any prepared Word or ASCII document. Features of this program include syntax coloration, as well as auto addition of HTML tagging for lists, paragraphs, forms, backgrounds/colours, etc. The auto addition of HTML code is completed through 4 toolbars, an HTML 2.0 spec tags, HTML 3.0 spec tags, customizable, and forms toolbar. It is available for Macintosh and Windows.

\section{Home Page}

Home Page is a WYSIWYG HTML editor that supports frames, tables, form tools, Java applets, multimedia plug-ins (i.e., Shockwave and Quicktime), and more. A direct source code HTML editing option is provided. The publish feature facilitates easy site consolidation and upload of files to the chosen server. It is available for Macintosh and Windows. 
SITE MANAGEMENT/HTML EDITING TOOLS

\section{Adobe SiteMill}

Adobe SiteMill offers an easy solution to managing HTML documents and their links at new and existing sites. Links can be checked and corrected with simple drag-and-drop of a file in both HTML and PDF documents. Currently, this application is included with PageMill for the Macintosh, but can be used with various other editors.

\section{GoLive CyberStudio}

CyberStudio, going beyond a basic WYSIWYG editor, offers many helpful features enabling one to completely design and publish a website. Pages can be edited within the layout, HTML code, or the unique outline editor mode, all of which are accompanied by helpful tool palettes. Site document and graphical management capabilities are also included. There is a built-in JavaScript Actions and Development Kit for easy script building. CyberStudio supports multimedia and colour technology through QuickTime editing and ColorSync. It is available for Macintosh.

\section{HoTMetal Pro}

This application offers three editing environments, which include a WYSIWYG graphical HTML editing mode, an HTML-Tag view mode, and a direct HTML source code editing mode. HoTMetal Pro provides helper features such as (1) Site Maker and a step-by-step tutorial for creating a website without exposure to HTML; (2) Information Manager, a visual means by which one can manage site documents and links; (3) Power Tools, a collection of the latest tools including a personal web server, databaseenabling software, Java editor, VRML creator, and animated GIF tool; (4) FX, a drag-and-drop collection of Java applets and scripts, animated GIFs, image maps, and Dynamic HTML, and 
(5) an HTML syntax checker. In addition to this, HoTMetal Pro contains a frame, Cascading Style Sheet (CSS), and graphics editor, and offers the ability to import text from programs such as Microsoft Word, Corel Word Perfect, Microsoft Excel, and more. It is available for Windows.

\section{Macromedia Dreamweaver}

Macromedia Dreamweaver is both a "visual HTML" (WYSIWYG) and HTML source code editor. It can be used as a visual tool. Dreamweaver supports table and frame creation through a drag-and-drop environment, Cascading Style Sheet (CSS) standards, CSS-P (CSS positioning), Netscape Layers, and JavaScript (including image rollover effects, animations, etc.). Some site management capabilities are also included. Two of the most noteworthy features are link checking/editing and a library for commonly used content. It is available for Macintosh and Windows.

\section{Microsoft FrontPage}

Microsoft FrontPage includes a WYSIWYG editor, which provides frames and tables support, Microsoft Image Composer, Microsoft GIF Animator, and an archive of images for facile graphics incorporation. FrontPage supports the inclusion of Cascading Style Sheet (CSS), browser plug-ins, database content (performing dynamic database queries), Java applets, JavaScript, ActiveX controls, and Microsoft Visual Basic. Other features such as wizards and templates accelerate the building process. For existing sites, FrontPage offers an import function. To facilitate management capabilities, FrontPage offers a view of navigational links, folders, and all files, as well as its best management feature: automatic hyperlink updates. This web tool is available for Macintosh and Windows. 


\section{NetObjects Fusion}

NetObjects Fusion is unique in that it offers a "site-oriented approach" rather than a simple WYSIWYG page editor. In other words, it allows users to visually map out the site structure, make global changes, automatically update links, and construct and organize individual pages without using HTML or Dynamic HTML coding. Database publishing is also supported, although support varies according to platform. Once the site is designed, the entire site structure, including the HTML pages, is generated from a NetObjects database. It is available for both Macintosh and Windows.

\section{WebQuest}

In education, a WebQuest is a research activity in which students read, analyze, and synthesize information using the World Wide Web. WebQuest is an inquiry-oriented activity in which some or all of the information that learners interact with comes from the resources on the Internet, optionally supplemented with videoconferencing.

The WebQuest is valued as a highly constructivist teaching method, during which students actively build their own understanding of a topic. "Authentic," or real-world questions or problems are often researched, and students work cooperatively to find solutions.

\section{ADDITIONAL RESOURCES}

\section{Beginner's Guide to HTML}

The Beginners's Guide to HTML is an excellent resource both to learn HTML and to use as a quick reference. It addresses basic topics including what an HTML document is, what it requires, and how to put HTML documents on the Web. The rest of this site focuses on creating HTML documents. This guide does a 
great job of explaining markup tags, linking, images, tables, and more.

\section{Doctor HTML}

Doctor HTML is an HTML syntax checker provided by Thomas Tongue and Imagiware, Inc. To use this online utility, the user simply enters the URL of the HTML document to be analyzed. The output is an easy-to-understand summary. Doctor HTML will check form structure, hyperlinks, spelling, image syntax, and more. This analysis can be done on a single page or on an entire site. Also included at this site are other HTML resources.

\section{The Web Developer's Virtual Library}

The Web Developer's Virtual Library contains most everything one needs to know about Web development. This site, provided by Internet.com, contains articles, links, demos, and much more. Web topics addressed include authoring, HTML, software, multimedia, and general Internet topics. It also provides a glossary for quick access.

\section{Web Mastery}

The Web Mastery HyperNews Forums and Resource Lists contain informative discussions and links regarding various web authoring topics. Some of the topics include learning HTML, HTML editors, WWW, servers, HTML converters, and images.

\section{WebReference.com}

WebReference.com is a web authoring resource. It provides up-to-date valuable information on the latest tools, news, and skills. Best of all, this site will benefit the novice as well as the webmaster. This site offers online workshops, articles, contests, and more including the Webreference Update newsletter, a valuable resource. 


\section{Web 2.0}

There is an emerging group of tools that are server-based, where the software exists online, not requiring the software be installed on a personal computer. Below is a sample of some of the Web 2.0 tools that show promise for supporting digital storytelling.

1. Collaborative writing tools for script development and collaborative writing: www.writely.com or any wiki

2. Audio editing tools (primarily created to capture and publish podcasts online): www.odeo.com, www.podomatic.com

3. Image sharing tools (primarily created to share images online): www.flickr.com, www.photoBucket.com

4. Video editing tools (primarily created to create and publish short video clips online): www.bubbleShare.com, www. jumpCut.com, www.primaryAccess.org

5. Media publishing services (primarily created to share video online): www.vimeo.com, www.ourmedia.org, www.youtube.com, www.video.google.com

The short overview above shows that students have at their disposal quite enough tools for creating e-Portfolios in general, and multimedia Portfolios in particular.

The main problem not discussed so far is the publishing and saving of multimedia portfolios due to large volume of the files containing multimedia objects. Thus, if all of a student's work is stored in e-Portfolios for perpetuity, considering the size of multi-media files, how can universities manage such a huge volume of data? If they can, how will they maintain accessibility over the years as the file formats change? There is only a questionable history of this capability with digital technologies. How useful will electronic portfolios be for assessment and reaccreditation on campuses if implementation is spotty or nonstandardized? For implementation to work, years of preparation may be necessary within a department, programme or college. 
As to publishing e-Portfolios on discrete media (CD's, ZIP disks, DVD's), it is not acceptable, because of the high security risk and risk of loose. Another possibility is an Internet Accessible Web Site. The concept of a widely accessible Web site storage location is inherently very attractive. Being able to access one's materials from any location is convenient and increases the likelihood that students would take advantage of the storage facility. Security issues abound, however, and making a site secure and private can be costly in software and administration expenses. This approach can be rejected because of excessive security risk, intellectual property concerns, and high setup and administrative costs associated with a secure system.

The next possibility for e-Portfolio publishing is a Student Accessible File Server. In networked environments, the concept of using "shared" drives is well established and with most network operating systems, controlling access is relatively straightforward. There is a modest learning curve associated with this approach, but network file handling tends to be something that students tend to teach one another. Media costs have fallen dramatically and are now on the order of pennies per megabyte.

Among the above approaches for publishing, only the last two are based on network technologies. If one of them has to be chosen, preference should be given to using the File Server, because it is easy to use, relatively secure, easy to backup for redundancy purposes, has little chance of file loss, low administrative overhead costs, and relatively low program costs.

\section{REFERENCES}

Barrett H. C. (2006) Digital Stories in ePortfolios: Multiple Purposes and Tools, Retrieved from http://electronicportfolios.org/digistory/purposesmac. html 
Batson T. (2002). The Electronic Portfolio Boom: What's it All About. Retrieved from http:/ / campustechnology.com/articles/2002/11/the-electronic-portfolio-boom-whats-it-all-about.aspx?sc_lang=en

Spencer, L. Creating An Electronic Portfolio, Retrieved from: http://cte.jhu. edu/techacademy/fellows/spencer/webquest/lasindex.html http://web.barebones.com/products/bbedit/bbedit.html http://web20workgroup.com/ http://webquest.org/ http://WDVL.internet.com/ http://www.adobe.com/prodindex/pagemill/main.htm http://www.adobe.com/prodindex/pagemill/pagemill20/siteben.html http:/ / www.aolpress.com/press http://www.claris.com/products/claris/homepage/homepage.html http://www.go2web20.net/ http://www.golive.com/ http://www.hypernews.org/HyperNews/get/www/html/guides.html http://www.hyperstudio.com http://www.macromedia.com/software/dreamweaver/ http://www.microsoft.com/frontpage/ http://www.ncsa.uiuc.edu/General/Internet/WWW/HTMLPrimer.html http://www.netobjects.com/ http://www.sq.com/products/hotmetal/ http://www.telacommunications.com/crackerjack/ http://www.webreference.com/ http://www2.imagiware.com/RxHTML/ 